Research Article

\title{
Durability Study on High Calcium Fly Ash Based Geopolymer Concrete
}

\author{
Ganesan Lavanya and Josephraj Jegan \\ Department of Civil Engineering, University College of Engineering Ramanathapuram, Ramanathapuram 623 513, India \\ Correspondence should be addressed to Ganesan Lavanya; charulavanya@gmail.com
}

Received 3 July 2015; Accepted 9 November 2015

Academic Editor: Jamal Berakdar

Copyright ( 2015 G. Lavanya and J. Jegan. This is an open access article distributed under the Creative Commons Attribution License, which permits unrestricted use, distribution, and reproduction in any medium, provided the original work is properly cited.

This study presents an investigation into the durability of geopolymer concrete prepared using high calcium fly ash along with alkaline activators when exposed to $2 \%$ solution of sulfuric acid and 5\% magnesium sulphate for up to 45 days. The durability was also assessed by measuring water absorption and sorptivity. Ordinary Portland cement concrete was also prepared as control concrete. The grades chosen for the investigation were M20, M40, and M60. The alkaline solution used for present study is the combination of sodium silicate and sodium hydroxide solution with the ratio of 2.50 . The molarity of sodium hydroxide was fixed as 12 . The test specimens were $150 \times 150 \times 150 \mathrm{~mm}$ cubes, $100 \times 200 \mathrm{~mm}$ cylinders, and $100 \times 50 \mathrm{~mm}$ discs cured at ambient temperature. Surface deterioration, density, and strength over a period of 14, 28, and 45 days were observed. The results of geopolymer and ordinary Portland cement concrete were compared and discussed. After 45 days of exposure to the magnesium sulfate solution, the reduction in strength was up to $12 \%$ for geopolymer concrete and up to $25 \%$ for ordinary Portland cement concrete. After the same period of exposure to the sulphuric acid solution, the compressive strength decrease was up to $20 \%$ for geopolymer concrete and up to $28 \%$ for ordinary Portland cement concrete.

\section{Introduction}

Concrete is a widely used construction material for various types of structures due to its durability. The reduction in the carbon dioxide emission from cement production can contribute significantly to the turning down of the global thermostat. Utilization of waste materials has been encouraged in construction field for the production of cement and concrete because it contributes to reducing the consumption of natural raw materials as resource and also reducing emission of greenhouse gases [1]. Fly ash based geopolymer concrete, made up of fly ash, sand, coarse aggregate, and an alkaline solution of sodium hydroxide and sodium silicate, plays a significant role in its environmental control of greenhouse effects [2]. As a new material for construction, not much of information is available on the durability of geopolymer concrete. The service life and durability of a concrete structure strongly depend on its material transport properties, such as permeability, sorptivity, and diffusivity [3]. Permeability controls deteriorations of concrete in the aggressive environment, because the process of such deteriorations as carbonation and chloride and sulfates attack is governed by the fluid transportation in concrete [4].

The durability of concrete is also an important requirement for the performance of the structure in aggressive environments. Acid resistance is one of the essential properties for structural materials [5]. Sulfate attack is known to produce significant degradation in concrete structures. Therefore, much attention was drawn to provide an adequate protection for concrete in contact with surroundings with high content of sulfate ions [6].

Durability of alkali-activated slag based geopolymer concrete has been reported to have a superior durability in aggressive environments as compared to ordinary Portland cement (OPC) concrete [7]. Fly ash based geopolymer mortar specimens manufactured with varying alkali content showed varying degree of deterioration when exposed to sulfuric acid [8]. Geopolymer concrete was highly resistant to sulfuric acid in terms of a very low mass loss, less than 3\% [9]. Geopolymer made of class $\mathrm{F}$ fly ash exposed to $5 \%$ sulfuric 
TABle 1: Chemical Composition of Class C fly ash.

\begin{tabular}{lcccccccc}
\hline Elements & $\begin{array}{c}\text { Silicon } \\
\text { dioxide } \\
\left(\mathrm{SiO}_{2}\right)\end{array}$ & $\begin{array}{c}\text { Aluminium } \\
\text { oxide } \\
\left(\mathrm{Al}_{2} \mathrm{O}_{3}\right)\end{array}$ & $\begin{array}{c}\text { Ferric } \\
\text { oxide } \\
\left(\mathrm{Fe}_{2} \mathrm{O}_{3}\right)\end{array}$ & $\begin{array}{c}\text { Calcium } \\
\text { oxide } \\
(\mathrm{CaO})\end{array}$ & $\begin{array}{c}\text { Magnesium } \\
\text { oxide } \\
(\mathrm{MgO})\end{array}$ & $\begin{array}{c}\text { Sodium } \\
\text { oxide } \\
\left(\mathrm{Na}_{2} \mathrm{O}_{3}\right)\end{array}$ & $\begin{array}{c}\text { Sulphur } \\
\text { trioxide } \\
\left(\mathrm{SO}_{3}\right)\end{array}$ & $\begin{array}{c}\text { Loss of } \\
\text { ignition } \\
(\mathrm{LOI})\end{array}$ \\
\hline Composition, \% tested & 25.69 & 17.10 & 9.43 & 24.54 & 4.06 & 1.62 & 4.25 & 0.5 \\
Specified as per ASTM & $25-42$ & $15-21$ & $5-10$ & $17-32$ & $4-12.5$ & $0.8-6.0$ & $0.4-5.0$ & $0.1-1.0$ \\
\hline
\end{tabular}

TABLE 2: Mix proportions of GPC and OPC.

\begin{tabular}{|c|c|c|c|c|c|c|c|}
\hline \multicolumn{8}{|c|}{ Materials, $\mathrm{kg} / \mathrm{m}^{3}$} \\
\hline Grade & $\begin{array}{c}\text { Coarse aggregate } \\
(20 \mathrm{~mm})\end{array}$ & $\begin{array}{c}\text { Fine aggregate } \\
\text { (sand) }\end{array}$ & Fly ash & Cement & Water/cement & $\mathrm{Na}_{2} \mathrm{SiO}_{3}$ & $\mathrm{NaOH}$ \\
\hline M20 & 1379 & 567 & 383 & & - & 137 & 54.51 \\
\hline M40 & 1159 & 522 & 527 & - & - & 133.33 & 53.33 \\
\hline M60 & 1070 & 505 & 530 & - & - & 128.59 & 51.59 \\
\hline M20 & 1258 & 572 & - & 350 & 0.5 & - & - \\
\hline M40 & 1184 & 564 & - & 463 & 0.4 & - & - \\
\hline M60 & 1261 & 540 & - & 530 & 0.31 & - & - \\
\hline
\end{tabular}

acid solution exhibited best performance and had weight loss of $1.96 \%$ [10]. Geopolymer immersed in 5\% sulphuric acid had the best performance, which was attributed to its stable cross-linked aluminosilicate polymer structure [11]. Based on the literatures, it was observed that the geopolymer concrete exhibited very good performance on the durability aspect. This paper presents the study of the durability of class $\mathrm{C}$ fly ash based geopolymer concrete exposed to sulphuric acid and magnesium sulphate solution.

\section{Research Significance}

One of the important steps of geopolymer synthesis is curing in dry or steam conditions and thus till recently the research emphasis was on thermally cured geopolymer composites synthesized normally with one source material. Most research articles deal only with alkali-activated class F fly ash. Literature is either scant or silent in respect of geopolymer synthesis with the high calcium fly ash. Further, being able to cure and develop strength at ambient temperature conditions is very important in terms of practical application. Hardly, there is few research reported on the durability of ambient cured class $\mathrm{C}$ fly ash based geopolymer concrete. In view of the above discussion, the present research article assumes significance. The paper presents the durability study of class C fly ash as binder component in producing ambient cured geopolymer concrete.

\section{Materials and Methods}

3.1. Materials. Class C fly ash was obtained from Neyveli Lignite Corporation, having specific gravity 2.1 and specific surface $319 \mathrm{~kg} / \mathrm{m}^{2}$ used. The chemical compositions of the fly ash are shown in Table 1 . To activate the fly ash, commercial grade sodium hydroxide $(\mathrm{NaOH})$ and sodium silicate $\left(\mathrm{Na}_{2} \mathrm{SiO}_{3}\right)$ alkaline solution was used as alkaline activator.
Locally available river sand as fine aggregate with a specific gravity of 2.64 and coarse aggregates with a specific gravity of 2.60 were used for making geopolymer concrete.

3.2. Testing Procedures. All fly ashbasedgeopolymer concrete specimens (GPC) were prepared with an alkaline solution ratio (sodium silicate to sodium hydroxide) of 2.5 by mass, since the strength was maximum, when the ratio of sodium hydroxide and sodium silicate was 2.5 [12]. The grades of concrete chosen were based on IS 456-2000. The molarity of sodium hydroxide was chosen as 12 . The mix proportion for geopolymer concrete is given in Table 2. Both coarse and fine aggregates were used in saturated surface dry condition. The fly ash and the aggregates were first dry-mixed in a pan. Then the alkaline solution containing sodium hydroxide and sodium silicate was added and mixed. The cube specimens of size $150 \times 150 \times 150 \mathrm{~mm}$ and cylinder of size $100 \times 200 \mathrm{~mm}$ were casted. After casting, the specimens were covered using polythene sheets to avoid the evaporation. The test specimens were left to room temperature curing of $28^{\circ} \mathrm{C}$ to $31^{\circ} \mathrm{C}$. OPC specimens were also prepared for comparison purposes.

The sorptivity tests were undertaken for cylindrical specimens with $100 \mathrm{~mm}$ diameter and $50 \mathrm{~mm}$ height in accordance with ASTM C1585-04. The cylinders after demoulded were submerged in water for 45 days. After curing, the samples were dried in oven for 24 hours at $110^{\circ} \mathrm{C}$ temperature. The specimens were drowned with water level not more than $5 \mathrm{~mm}$ above the base of specimen and the flow from the peripheral surface is prevented by sealing it properly with nonabsorbent coating to maintain the uniaxial water flow during the test. The quantity of water absorbed in a time period of 30 minutes was measured. Finally the sorptivity coefficient was calculated using the equations given as follows:

$$
S=\frac{I}{\sqrt{t}},
$$


where $S$ is the sorptivity in $\mathrm{mm}$ and $t$ is the elapsed time in min. Consider

$$
I=\frac{\Delta W}{A D} .
$$

$\Delta W$ is change in weight which equals $W_{2}-W_{1}$, where $W_{1}$ is the oven dry weight of cylinder in grams and $W_{2}$ is the weight of cylinder after 30 minutes of capillary suction of water in grams, $A$ is the surface area of the specimen through which water penetrated, and $D$ is the density of water.

For water absorption test, $100 \times 50 \mathrm{~mm}$ cylinders after casting were immersed in water for 45 -day curing. These specimens were then oven-dried for 24 hours at the temperature $110^{\circ} \mathrm{C}$ until the mass became constant and again weighed. This weight was noted as the dry weight $\left(W_{1}\right)$ of the cylinder. After that the specimen was kept in hot water at $85^{\circ} \mathrm{C}$ for 3.5 hours. Then the weight was noted as the wet weight $\left(W_{2}\right)$ of the cylinder. Consider

$$
\% \text { water absorption }=\left[\frac{W_{2}-W_{1}}{W_{1}}\right] \times 100,
$$

where $W_{1}$ is the oven dry weight of cylinder in grams and $W_{2}$ is the wet weight of cylinder in grams after 3.5 hours.

The response of the geopolymer and ordinary cement concrete specimens in sulphuric acid and magnesium sulphate environment was studied by immersing the specimens in $2 \%$ sulphuric acid [13] and 5\% magnesium sulphate solution [14] separately after 7 days of casting. The choice of solution and concentration was based on practical utilization of concrete as a construction material in sewage pipes, mining, and food processing industries. The specimens were kept fully immersed in these solutions, having four times the volume of specimens for 45 days. The solutions were replaced weekly with fresh solutions in order to maintain the concentration of the solution [15]. The effects of these solutions on the specimens were regularly monitored through visual inspection, measurement of weight change, and strength test. Samples for weight change test were primed in water for 3 days prior to immersion in these solutions and its saturated surface dry weight was considered as initial weight. These samples were removed from the solution and weighed at various stages of exposure in similar condition as the final weight.

\section{Results and Discussion}

4.1. Sorptivity. Sorptivity is the measure of water absorption rate front through the unsaturated concrete under capillary suction. The results of the sorptivity tests are presented in Figure 1. The incorporation of pozzolan such as fly ash reduces the average pore size and results in a less permeable paste which helps in achieving high strength, low permeability, and durable concrete [16]. Minimising sorptivity is important in order to reduce the ingress of chloride or sulphate into concrete [17]. The sorptivity of the geopolymer concrete gets increased with the increase in grade. The increase in the fly ash content increases the sorptivity [18]. The specimens with lower sorptivity and water absorption

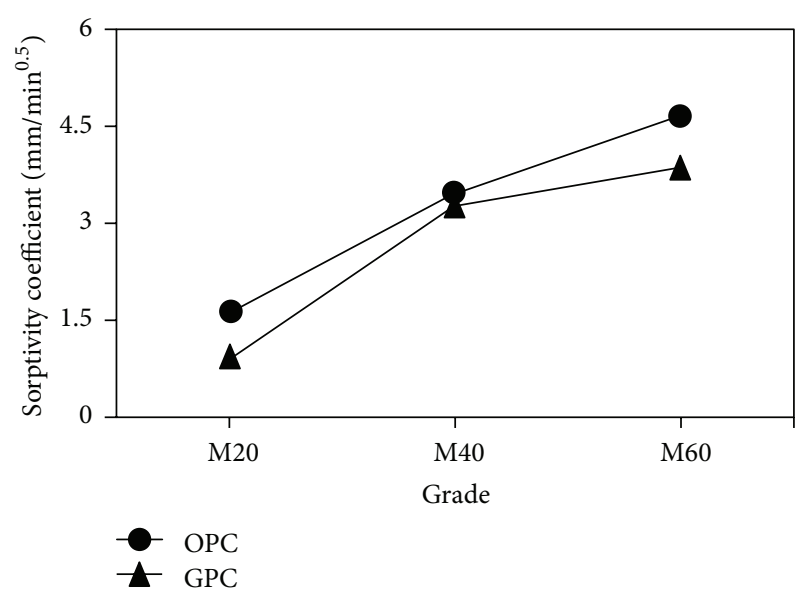

FIgure 1: Sorptivity Co efficient for OPC and GPC.



FIGURE 2: Water absorption for OPC and GPC.

yielded higher residual compressive strength [19] as can be observed in the current study.

4.2. Water Absorption. The trend shown in Figure 2 indicated that the water absorption increased linearly with grades of geopolymer concrete. The increase in water absorption indicated the presence of higher void content due to incomplete process of geopolymerization. The lower water absorption was observed in geopolymer concrete compared to ordinary Portland cement concrete. The presence of higher silica content formed higher quantity of aluminosilicate gel and provides very good interparticle bonding. Hence, the silicate occupies the void spaces between the fly ash particles resulting in lower water absorption [20].

4.3. Resistance to Sulphate Attack. Figure 3 shows the visual appearance of the geopolymer concrete specimens after immersion in magnesium sulphate solutions. It was observed that the geopolymer concrete specimens' visual appearance was somewhat similar when compared to the OPC concrete specimens. The geopolymer concrete specimens had no significant change in appearance after 45 days of exposure to 




Figure 3: Geopolymer specimens exposed to 5\% magnesium sulphate solution.

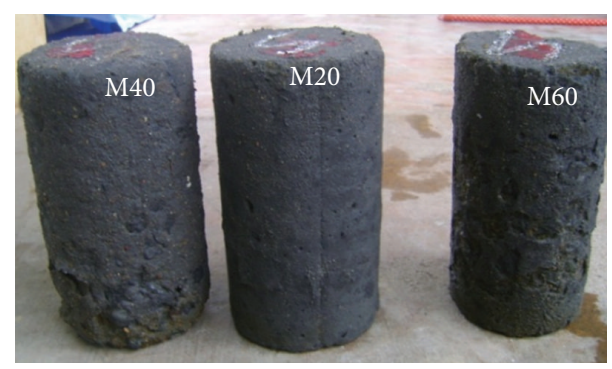

FIGURE 4: Geopolymer specimens exposed to $2 \%$ sulphuric acid solution.

magnesium sulphate solutions. However, specimens seemed to be slightly damaged at the surface and around the edges of specimens in addition to more pores. The presence of efflorescence was observed on the surface due to presence of high calcium hydration products in geopolymer specimens as shown in Figure 5. The sulphate attack on magnesium ions leads to gypsum precipitation and decalcification of C-S-H which destroys the binding capacity of C-S-H and leads to a loss of adhesion and strength in concrete [6]. The calcium hydration product was susceptible to the attack of the acid solution and if present in large quantity should cause the deterioration of the mortar. Therefore, the geopolymer concrete specimens and OPC concrete specimens showed the deterioration and wear down on the surface and edges. As can be seen from Figure 1, the specimens of M40 and M60 immersed in the magnesium sulfate have similar appearances except M20. M40 and M60 grade specimens show a sign of slight deterioration, white deposits, whereas for M20 grade, only the loss of glossy appearance can be seen. It can be seen from Figure 6 that the visual appearance of the OPC specimens after 45 days of exposure showed no appreciable change in the appearance of the specimens.

Figure 7 represents the density of specimens exposed to magnesium sulphate up to 45 days for M20, M40, and M60 grades. After 45 days of exposure, the density of geopolymer concrete specimens had gradually decreased with an increase in time. The decrease in density for all the grades was observed in the range of 4 to $6 \%$ in OPC, whereas it was about 2 to $3 \%$ in GPC when exposed to magnesium sulphate. The formation of gypsum as a result of cation exchange reactions

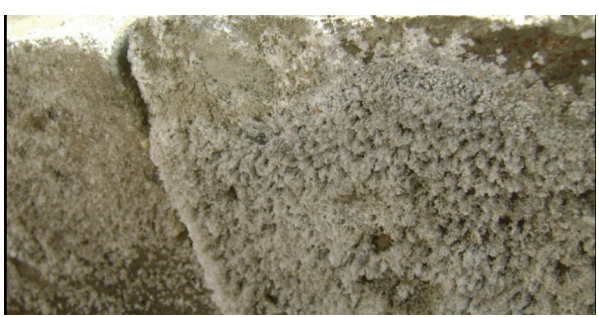

FIgURE 5: White deposits on geopolymer specimens exposed to magnesium sulphate solution.

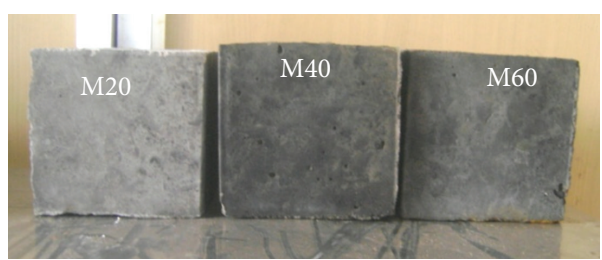

FIGURE 6: OPC specimens exposed to magnesium sulphate and sulphuric acid solution.

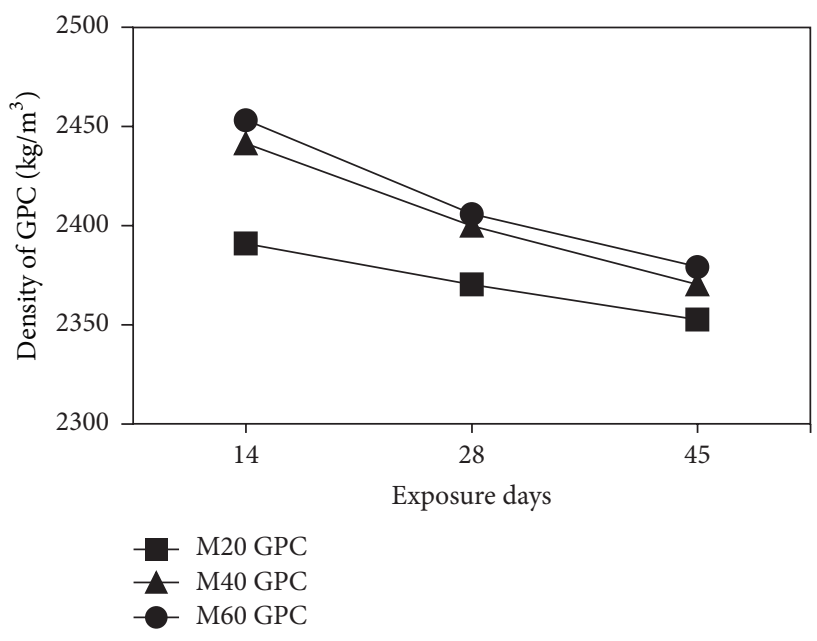

FIGURE 7: Density of GPC exposed to magnesium sulphate solution.

is also capable of causing expansion but is normally linked to loss of mass and strength [21].

The residual compressive strength has been used to evaluate the acid resistance of geopolymer concrete because of the rough surface and the exposed aggregate after acid immersion. Geopolymer concrete remains structurally intact. The compressive strength was used to evaluate the impact of acid attack on mechanical performance. As seen from Figure 9, the strength reduction was significant for all the grades except M20. The strength loss of geopolymer concrete was measured in the range of $5-12 \%$, whereas it was about 5 to $25 \%$ in OPC. In the presence of the calcium hydroxide formed in cement paste, when the latter comes in contact with sulphate ions, the alumina containing hydrates are converted to the high sulphate form ettringite. These ettringite crystals grow, expand, or swell by mechanisms. The residual load capacity indicates that some bonds still exist even when the 




FIGURE 8: Density of GPC exposed to sulphuric acid solution.

specimen was neutralized by acid [22]. In addition, it is very interesting to compare the acid resistance between the grades. The high calcium presented in the source material makes the main geopolymerization products less susceptible to sulfate attack [23]. Therefore, M20 has higher compressive strength than other grades.

4.4. Resistance to Sulphuric Acid. Figure 4 shows the physical appearance of the geopolymer specimens of M20, M40, and M60 after 45 days of immersion in sulphuric acid. The specimens seemed to be slightly damaged at the surface and around the edges of specimens and the aggregates are clearly visible. Also, some fine localized cracks were observed. It has been observed that the surface of the specimens was badly eaten up and aggregates are clearly visible. The M20 specimens in $2 \%$ sulfuric acid solution were not that much damaged when compared to other grades. Figure 6 shows the visual appearance of the OPC specimens after 45 days of exposure showed no appreciable change in the appearance of the specimens.

Figure 8 represents the density of specimens exposed to sulfuric acid up to 45 days for M20, M40, and M60 grades. After 45 days of exposure period, the density of geopolymer concrete specimens had gradually decreased with an increase in exposure period. The decrease in density was observed in the range of 5 to $7 \%$ in OPC, whereas it was about 2.5 to $4 \%$ in GPC when exposed to sulphuric acid. The decreases in density were primarily due to the reaction between calcium hydroxide presented specimens and the acid, which can induce tensile stress, resulting in cracking and scaling of concrete [24]. In addition, the siliceous compounds in fly ash reacted to form a more stable product of C-S-H that further filled the pores in mortars [25].

The reduction in the density was also dependent on the fineness of fly ash [26]. The small particles of the fly ash allowed a denser packing of the mixture. Therefore geopolymer specimens yielded lower density. The surface of the fly ash particles was not smooth and therefore provides

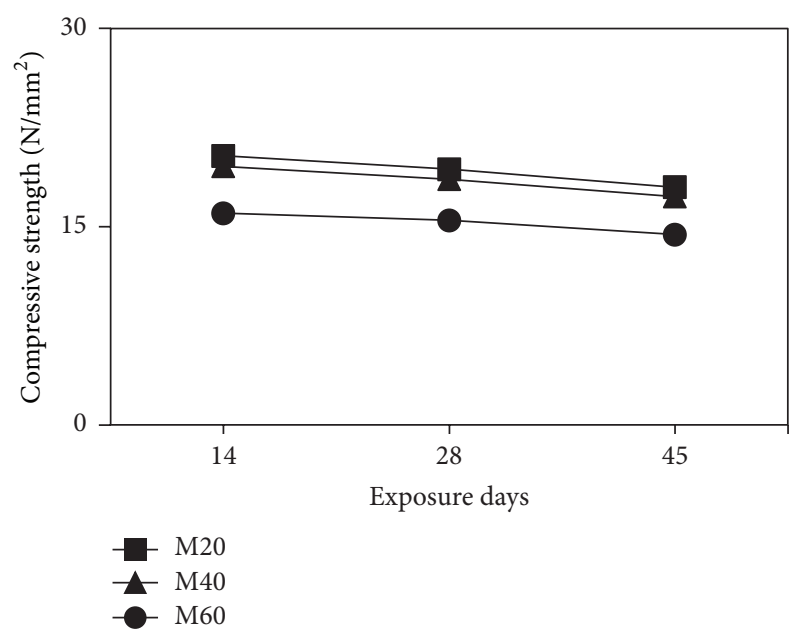

FIGURE 9: Compressive strength of GPC exposed to magnesium sulphate solution.



FIGURE 10: Compressive strength of GPC exposed to sulphuric acid solution.

good bonding and would result in a smaller weight loss due to the sulfuric acid attack.

Figure 10 shows the evolution of the compressive strength of the specimens exposed to the sulfuric acid solution. The geopolymer concrete specimens had $12-20 \%$ strength loss after 45 days of exposure to sulphuric acid. This may be attributed to the breakage of aluminosilicate bonding in geopolymer concrete caused by the sulfuric acid attack [10], because aluminosilicate bonding is important as it gives strength to geopolymer concrete. In contrast, the OPC concrete specimens had 18-28\% strength loss of sulfuric acid exposure. The rate of decrease of strength decreased with increase in fly ash content [27]. Among geopolymer concrete, M20 performed significantly better than the others. The high content of fly ash underwent less geopolymerization and less hydration associated with the calcium as compared to those of less amount of fly ash as indicated by the strength results [28]. 


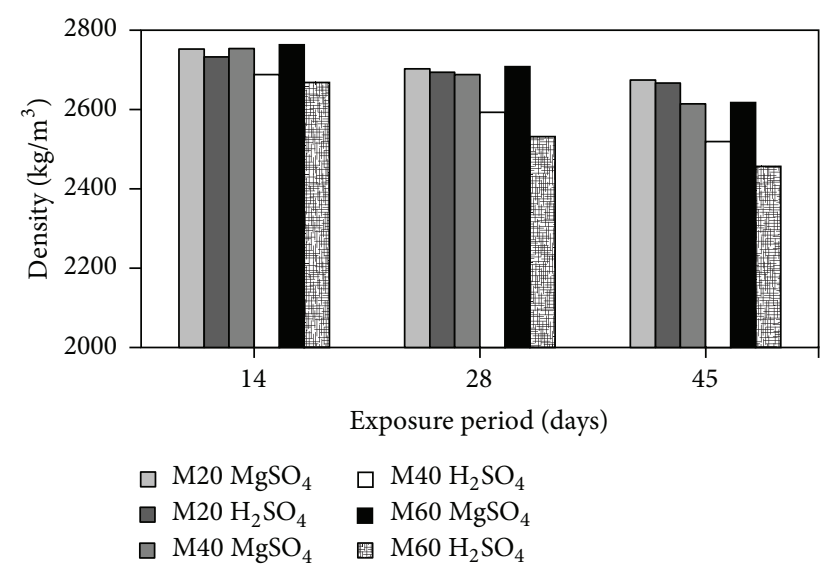

FIGURE 11: Density of OPC exposed to magnesium sulphate and sulphuric acid solution.

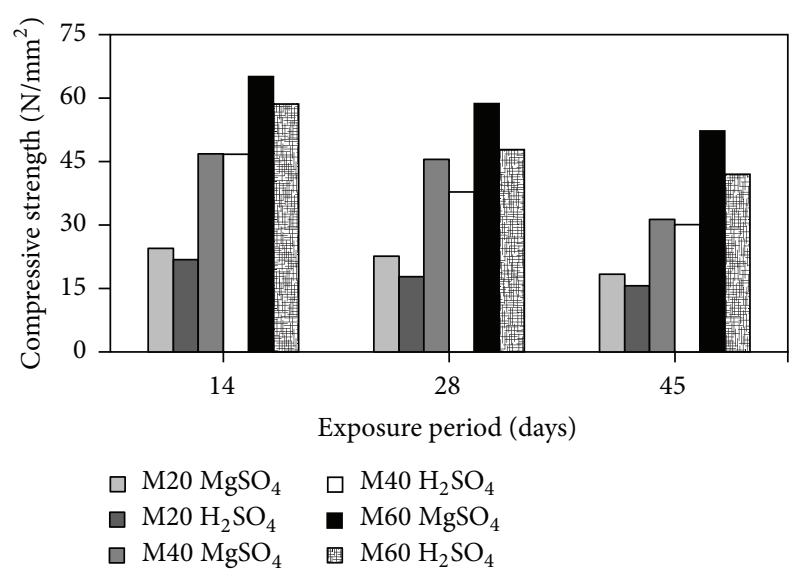

FIGURE 12: Compressive strength of OPC exposed to magnesium sulphate and sulphuric acid solution.

Figures 11 and 12 show the density and compressive strength of OPC.

\section{Conclusions}

This study presents the investigations of the resistance on magnesium sulphate and sulphuric acid solutions of geopolymer concrete and OPC. Based on the results, the following conclusions can be drawn.

(1) The GPC and OPC mixes indicated minor changes in weight and strength when the specimens were exposed to sulphuric acid and magnesium sulphate.

(2) The compressive strength loss from 7 to 45 days of exposure in sulphuric acid was in the range of 18 to $28 \%$ in OPC, whereas it was about 12 to $20 \%$ in GPC.

(3) The compressive strength loss from 7 to 45 days of exposure in magnesium sulphate was in the range of 5 to $25 \%$ in OPC, whereas it was about 5 to $12 \%$ in GPC.
(4) The decrease in density was observed in the range of 5 to $7 \%$ in OPC, whereas it was about 2.5 to $4 \%$ in GPC when exposed to sulphuric acid.

(5) The decrease in density was observed in the range of 4 to $6 \%$ in OPC, whereas it was about 2 to $3 \%$ in GPC when exposed to magnesium sulphate.

(6) The water absorption and sorptivity of geopolymer concrete showed lower water absorption and sorptivity when compared to ordinary Portland cement concrete for M20, M40, and M60 grade concrete.

\section{Conflict of Interests}

The authors declare that there is no conflict of interests regarding the publication of this paper.

\section{References}

[1] D. Hardjito, S. E. Wallah, D. M. J. Sumajouw, and B. V. Rangan, "On the development of fly ash-based geopolymer concrete," ACI Materials Journal, vol. 101, no. 6, pp. 467-472, 2004.

[2] A. M. Fernández-Jiménez, A. Palomo, and C. López-Hombrados, "Engineering properties of alkali-activated fly ash concrete," ACI Materials Journal, vol. 103, no. 2, pp. 106-112, 2006.

[3] N. S. Martys, "Survey of concrete transport properties and their measurement," NISTIR 5592, US Department of Commerce, Washington, DC, USA, 1996.

[4] M. G. Alexander and B. J. Magee, "Durability performance of concrete containing condensed silica fume," Cement and Concrete Research, vol. 29, no. 6, pp. 917-922, 1999.

[5] T. Bakharev, J. G. Sanjayan, and Y.-B. Cheng, "Resistance of alkali-activated slag concrete to acid attack," Cement and Concrete Research, vol. 33, no. 10, pp. 1607-1611, 2003.

[6] T. Bakharev, J. G. Sanjayan, and Y.-B. Cheng, "Sulfate attack on alkali-activated slag concrete," Cement and Concrete Research, vol. 32, no. 2, pp. 211-216, 2002.

[7] D. M. Roy and G. M. Idorn, "Hydration, structure, and properties of blast furnace slag cements, mortars and concrete," ACI Material Journal, vol. 79, no. 12, pp. 444-457, 1982.

[8] S. Thokchom, P. Ghosh, and S. Ghosh, "Acid resistance of fly ash based geopolymer mortars," International Journal of Recent Trends in Engineering, vol. 1, no. 6, pp. 36-40, 2009.

[9] X. J. Song, M. Masrosszeky, M. Brungs, and R. Munn, "Durability of fly ash based geopolymer concrete against sulphuric acid attack," in Proceedings of the International Conference on Durability of Building Materials and Components, France, 2005.

[10] T. Bakharev, "Resistance of geopolymer materials to acid attack," Cement and Concrete Research, vol. 35, no. 4, pp. 658-670, 2005.

[11] T. Bakharev, "Durability of geopolymer materials in sodium and magnesium sulfate solutions," Cement and Concrete Research, vol. 35, no. 6, pp. 1233-1246, 2005.

[12] S. H. Sanni and R. B. Khadiranaikar, "Performance of geopolymer concrete under severe environmental conditions," International Journal of Civil and Structural Engineering, vol. 3, no. 2, pp. 396-407, 2012.

[13] N. P. Rajamane, M. C. Nataraja, N. Lakshmanan, J. K. Dattatreya, and D. Sabitha, "Sulphuric acid resistant ecofriendly concrete from geopolymerisation of blast furnace slag," Indian Journal of Engineering and Materials Sciences, vol. 19, no. 5, pp. 357-367, 2012. 
[14] M. Malviya and H. S. Goliya, "Durability of fly ash based geopolymer concrete using alkaline solutions $(\mathrm{NaOH}$ and $\mathrm{Na}_{2} \mathrm{SiO}_{3}$ )," International Journal of Emerging Trends in Engineering and Development, vol. 6, no. 4, pp. 18-33, 2014.

[15] S. E. Wallah and B. V. Rangan, "Low-calcium fly ash-based geopolymer concrete: long-term properties," Research Report GC 2, Faculty of Engineering, Curtin University of Technology, Perth, Australia, 2006.

[16] P. Chindaprasirt, C. Jaturapitakkul, and T. Sinsiri, "Effect of fly ash fineness on compressive strength and pore size of blended cement paste," Cement and Concrete Composites, vol. 27, no. 4, pp. 425-428, 2005.

[17] W. J. McCarter, H. Ezirim, and M. Emerson, "Absorption of water and chloride into concrete," Magazine of Concrete Research, vol. 44, no. 158, pp. 31-37, 1992.

[18] Folagbade and S. Olufemi, "Effect of fly ash and silica fume on the sorptivity of concrete," International Journal of Engineering Science and Technology, vol. 4, no. 9, pp. 4238-4246, 2012.

[19] S. Thokchom, P. Ghosh, and S. Ghosh, "Effect of water absorption, porosity and sorptivity on durability of geopolymer mortars," Journal of Engineering and Applied Sciences, vol. 4, no. 7, pp. 28-32, 2009.

[20] K. Ghosh and P. Ghosh, "Effect of $\% \mathrm{Na}_{2} \mathrm{O}$ and $\% \mathrm{SiO}_{2}$ on apperent porosity and sorptivity of fly ash based geopolymer," IOSR Journal of Engineering, vol. 2, no. 8, pp. 96-101, 2012.

[21] T. Cao, L. Bucea, and O. Ferguson, "Sulphate resistance of cementitious materials-mechanisms, deterioration processes, testing and influence of binder," in Proceedings of the For the future: Concrete '97-18th Biennial Conference, pp. 263-268, Concrete Institute of Australia, Adelaide, Australia, May 1997.

[22] X. J. Song, M. Marosszeky, M. Brungs, and R. Munn, "Durability of fly ash based Geopolymer concrete against sulphuric acid attack," in Proceedings of the DBMC International Conference on Durability of Building Materials and Components, Lyon, France, April 2005.

[23] V. Sata, A. Sathonsaowaphak, and P. Chindaprasirt, "Resistance of lignite bottom ash geopolymer mortar to sulfate and sulfuric acid attack," Cement and Concrete Composites, vol. 34, no. 5, pp. 700-708, 2012.

[24] M. A. M. Ariffin, M. A. R. Bhutta, M. W. Hussin, M. Mohd Tahir, and N. Aziah, "Sulfuric acid resistance of blended ash geopolymer concrete," Construction and Building Materials, vol. 43, pp. 80-86, 2013.

[25] S. Aydin, H. Yazici, H. Yiǧiter, and B. Baradan, "Sulfuric acid resistance of high-volume fly ash concrete," Building and Environment, vol. 42, no. 2, pp. 717-721, 2007.

[26] P. Chindaprasirt, S. Homwuttiwong, and V. Sirivivatnanon, "Influence of fly ash fineness on strength, drying shrinkage and sulfate resistance of blended cement mortar," Cement and Concrete Research, vol. 34, no. 7, pp. 1087-1092, 2004.

[27] M. Vaishnavi and M. K. Rao, "Durability of high volume fly ash concrete," International Journal of Engineering Research and Technology, vol. 3, no. 8, pp. 872-876, 2014.

[28] P. Chindaprasirt, T. Chareerat, and V. Sirivivatnanon, "Workability and strength of coarse high calcium fly ash geopolymer," Cement and Concrete Composites, vol. 29, no. 3, pp. 224-229, 2007. 

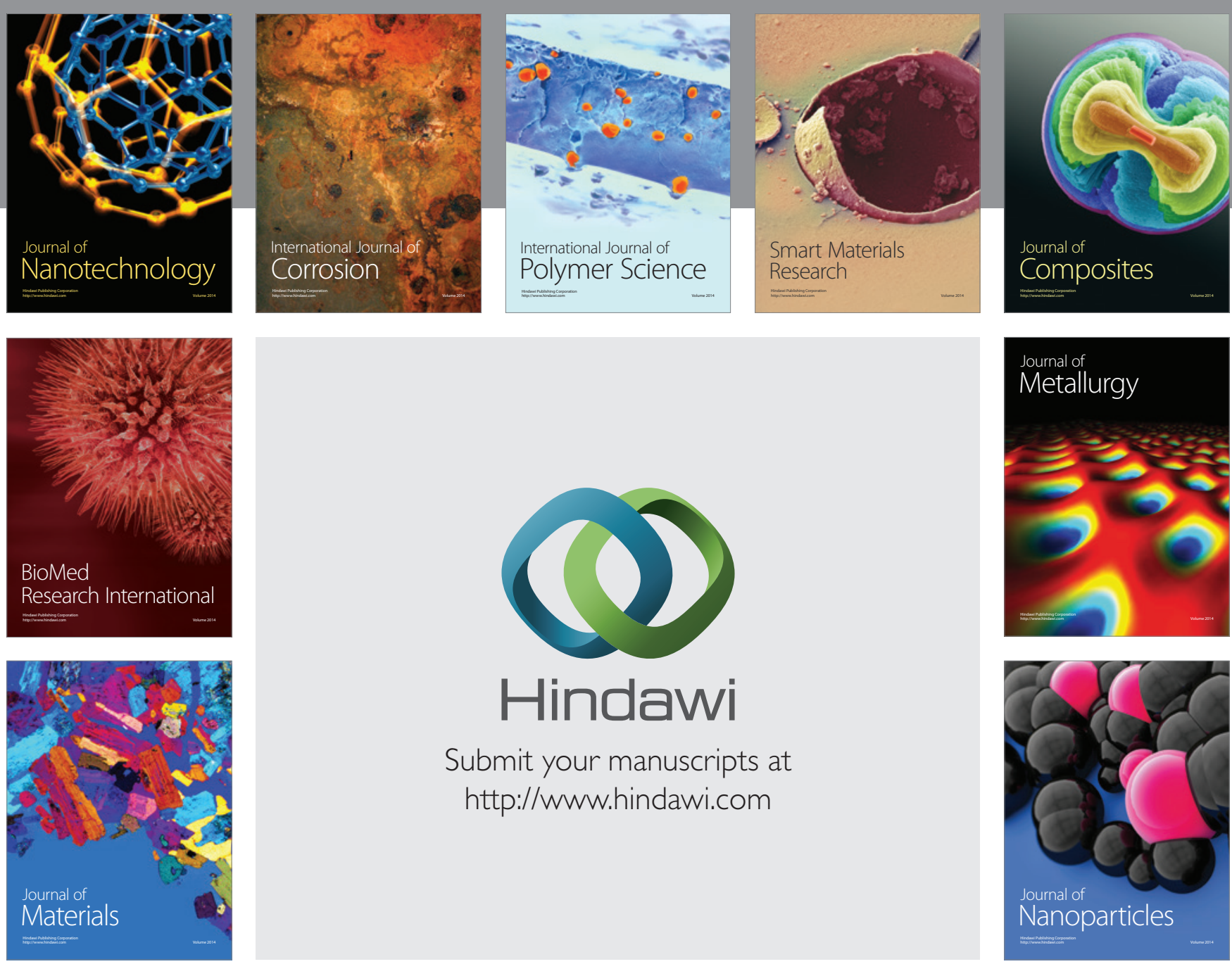

Submit your manuscripts at http://www.hindawi.com
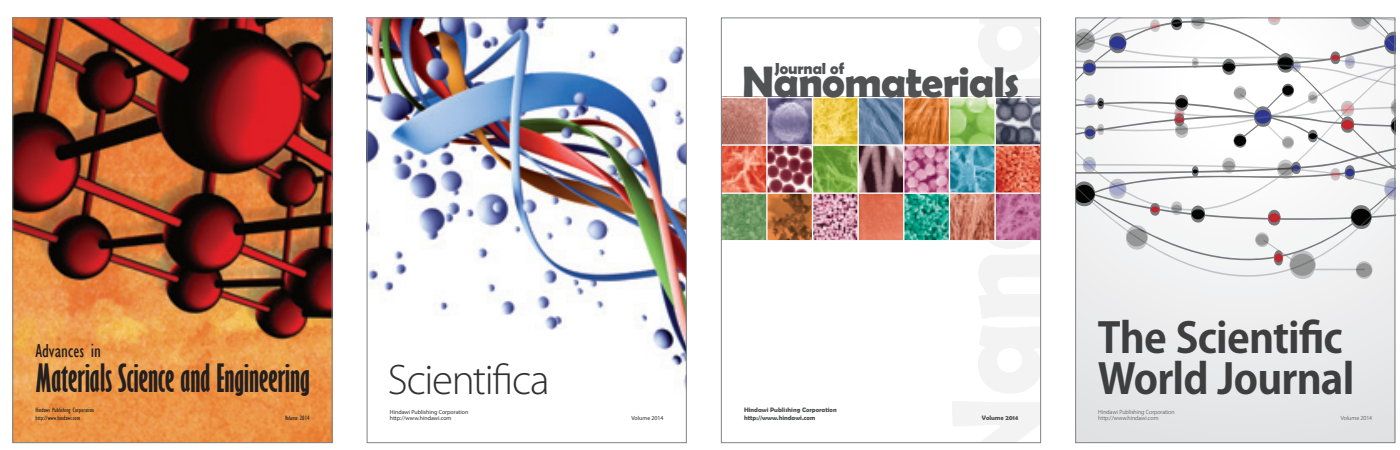

\section{The Scientific World Journal}
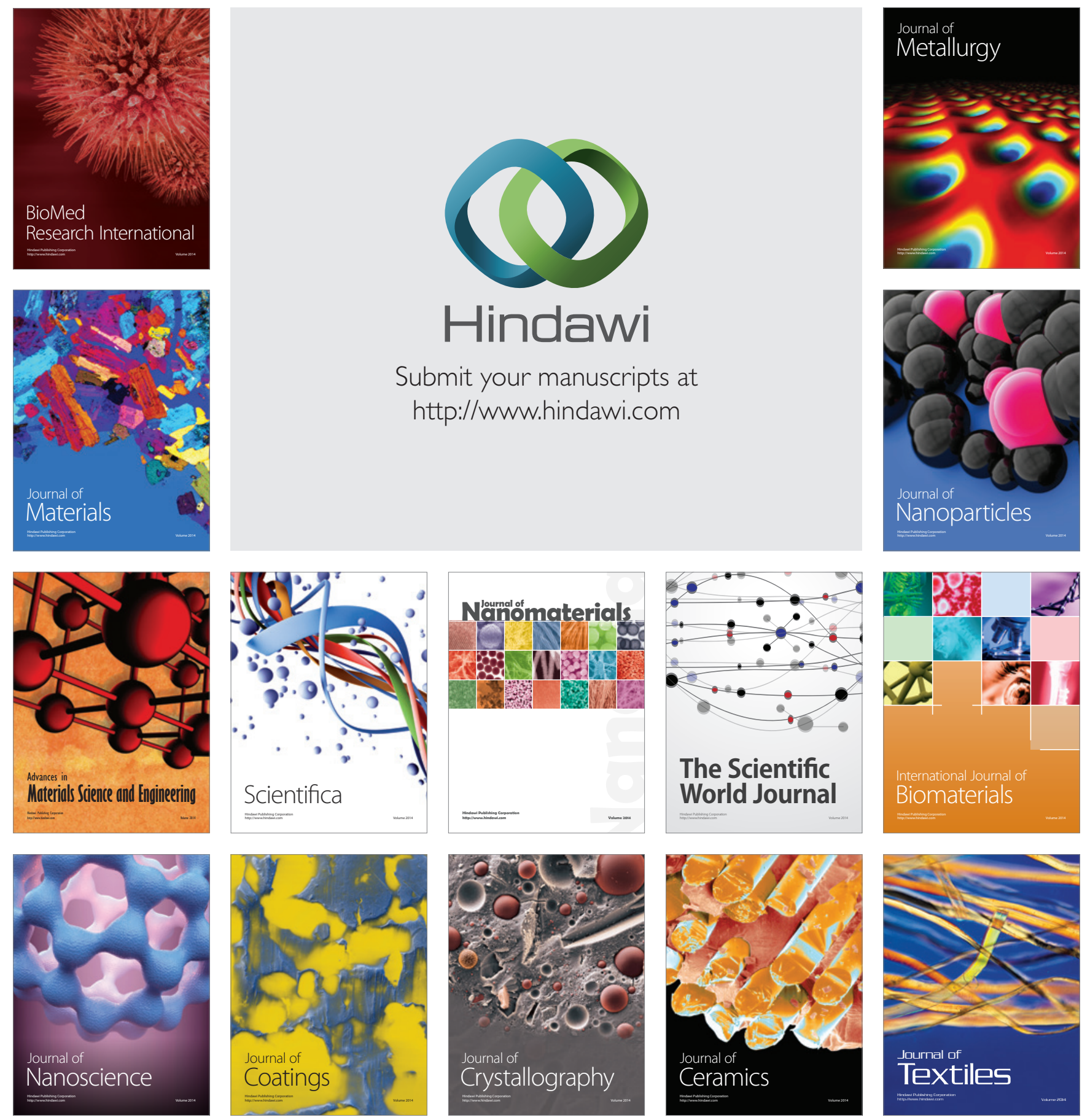